is clear: having been forced to act as her blind sister's guide she has felt neglected, then despised, and has finally drifted through self-loathing back to the role of dog, this time in the insulting sense of the word as a rough, tough, sexual pushover.

But the most striking feature of Cracker isthe profession of its central character. Although fiction has for decades played on the supposed link between the methods of medicine and crime-busting (Conan Doyle of course based Holmes on Joseph Bell, an Edinburgh surgeon), previous detectives have not been specialists in mental illness. Twenty years ago a successful series called The Expert highlighted the deductive powers of the forensic pathologist. Now, thanks to a popular fascination with psychological profiling of criminals, it is the turn of the psychologist.
The media have given profiling a largely uncritical press and the makers of Cracker could have been excused if they had swallowed its pretentions whole. But they did not. Although for dramatic effect they made its methods appear cleverly intuitive, they also ended the series on a sour, sceptical note. Fitz eventually persuades a confession from someone he has always been sure is a child-killer. But in private the man withdraws his admission. You're not angry for the dead boy, he tells Fitz, you're angry because you were wrong, because you are not as good as you think. To their credit, the programme makers knew not to trust someone who claimed his instincts as science.

Louis Appleby, Senior Lecturer, University of Manchester, Withington Hospital, West Didsbury, Manchester M20 8LR

\title{
The psychiatrist, the hero and the romance genre
}

\author{
Jacqueline M. Atkinson
}

Until recently psychiatrists were all but unheard of in romantic fiction which is dominated in Britain by the publishers Mills \& Boon. In the UK, there is a strong interest in imedical romances' not exhibited in other countries, and Mills \& Boon publish four Medical Romances (formerly called Doctor-Nurse Romances and from autumn 1993 'Love on Call') every month. This is in contrast to what appears in the United States, for example, where medical romances are almost unknown.

Stories about psychiatry tend to do less well than those about other illnesses, and certain subjects are taboo. Alzheimer's disease seems to be a particular no-go area. The reasons for this seem to be that there remains a generally negative public attitude to mental illness, and that the readers of such medical romances are older than readers of more contemporary romances: anything that is too close to home is generally unwelcome in these books. But this does not mean that the reality of mental illness is denied. In Delicate Harmony, for example, one of the central minor characters, a young male patient, commits suicide, albeit offstage. It is interesting that the most popular of these books is Tansy's Children which deals with disturbed children rather than adults.

Are there other reasons for the scarcity of psychiatrist-heroes? As well as describing a 'hero' as 'the chief male personage in a story' the Shorter Oxford Dictionary reminds us of other characteristics: men of superhuman strength, courage or ability; who exhibit extraordinary bravery or greatness of soul; admired and venerated for his achievements and noble qualities. In Mills \& Boon, besides being tall, dark and handsome, heroes are also dynamic, forceful, strong, in control and frequently leaders. How does this fit the practice of psychiatry? And how does this compare with the more frequent portrayal of psychiatrists in films?

All the Mills \& Boon stories are based in an institution of some kind, be it 'clinic' or hospital, with little evidence of movement into the community, although Pride's Fall deals with moving patients from a hospital setting to shared flats in the community and Doctor Alone is concerned 


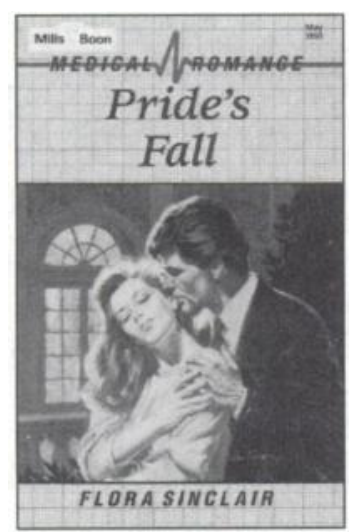

with the impact of schizophrenia and head injury on families as carers. Treatments include medication, psychotherapy, behaviour therapy, family therapy, family psychoeducation and general family and patient support. In American films psychiatrists are rarely seen to prescribe medication, and when they do they are usually criticised or it is seen as 'an easy option' and a poor substitute for 'understanding'. Other interventionist techniques, such as ECT, are almost always described negatively and as punishment (e.g. The Snake Pit and One Flew Over the Cuckoo's Nest). The 'cathartic cure' so beloved in films appears less in Mills \& Boon, possibly reflecting the professional background of some authors. Within the limitations of the genre, therefore, there is evidence that the authors are trying to portray a clinical reality.

In films many psychiatrists remain faceless, even nameless (Diary of a Mad Housewife, Interiors) and we learn little of their personal lives. When we do, we usually discover problems. It is as though being a psychiatrist gets in the way of personal relationships - a view echoed to a large extent by the ill-fated television series Shrinks. In contrast, in Mills \& Boon the focus of the story is the personal life of the protagonists. The nurse heroine in Delicate Harmony has some problems which have to be overcome before she can allow a relationship to develop, although this should not be seen as exclusive to those working in mental health. In Mills \& Boon both hero and heroine commonly have 'problems' or 'dark secrets' that lead to the necessary conflict between them before being resolved at the happy ending.

Does this way of portraying psychiatry, with the psychiatrist as a hero in spite of rather than because of his profession, matter? Could it be positive? Mills \& Boon reach a large number of readers. Print runs are confidential but it is generally accepted that the only reason Mills \& Boon do not appear in best seller lists is because a high proportion of their sales are not through bookshops. An indication of their possible range of influence can still be crudely assessed by looking at borrowing from libraries. An estimate of national loans is made for the payment of Public Lending Rights (PLR). For the PLR year July 1991 June 1992 Doctor Alone was borrowed 20,000 times. Not in the Catherine Cookson league, certainly, but considerably greater than the borrowing in the same period of a lay guide to schizophrenia which was borrowed an estimated 6,600 times.

Attitudes to the mentally ill tend to be fearful, negative and frequently misinformed, and the best way of reducing fear of something is to present it in a controlled, safe environment. Although frequently decried for their predictability it is this very quality that allows Mills \& Boon romances to depict psychiatry in a nonthreatening fashion. If people are to be less frightened by mental illness and psychiatry then they need to encounter it as part of their everyday lives. For readers of romance, psychiatry in Mills \& Boon makes it accessible; it makes it ordinary.

Jacqueline M. Atkinson, Senior Lecturer in Behavioural Science, Department of Public Health, University of Glasgow, 2 Lillybank Gardens, Glasgow G12 8RZ 